\title{
Effect of androgen on Kiss1 expression and luteinizing hormone release in female rats
}

\author{
Kinuyo Iwata, Yuyu Kunimura, Keisuke Matsumoto and Hitoshi Ozawa \\ Department of Anatomy and Neurobiology, Graduate School of Medicine, Nippon Medical School, \\ Bunkyo-ku, Tokyo, Japan
}

Correspondence should be addressed to K Iwata Email

kiwata0309@nms.ac.jp

\begin{abstract}
Hyperandrogenic women have various grades of ovulatory dysfunction, which lead to infertility. The purpose of this study was to determine whether chronic exposure to androgen affects the expression of kisspeptin (ovulation and follicle development regulator) or release of luteinizing hormone (LH) in female rats. Weaned females were subcutaneously implanted with 90-day continuous-release pellets of $5 \alpha$-dihydrotestosterone (DHT) and studied after 10 weeks of age. Number of Kiss 1 expressing cells in both the anteroventral periventricular nucleus (AVPV) and arcuate nucleus (ARC) was significantly decreased in ovary-intact DHT rats. Further, an estradiolinduced LH surge was not detected in DHT rats, even though significant differences were not observed between DHT and non-DHT rats with regard to number of AVPV Kiss1-expressing cells or gonadotrophin-releasing hormone ( $\mathrm{GnRH}$ )-immunoreactive (ir) cells in the presence of high estradiol. Kiss1-expressing and neurokinin B-ir cells were significantly decreased in the ARC of ovariectomized (OVX) DHT rats compared with OVX non-DHT rats; pulsatile LH secretion was also suppressed in these animals. Central injection of kisspeptin-10 or intravenous injection of a GnRH agonist did not affect the LH release in DHT rats. Notably, ARC Kiss1-expressing cells expressed androgen receptors (ARs) in female rats, whereas only a few Kiss1-expressing cells expressed ARs in the AVPV. Collectively, our results suggest excessive androgen suppresses LH surge and pulsatile LH secretion by inhibiting kisspeptin expression in the ARC and disruption at the pituitary level, whereas AVPV kisspeptin neurons appear to be directly unaffected by androgen. Hence, hyperandrogenemia may adversely affect ARC kisspeptin neurons, resulting in anovulation and menstrual irregularities.
\end{abstract}

\section{Introduction}

Hyperandrogenism is a state characterized by excessive levels of androgens. Commonly diagnosed disorders involving hyperandrogenism in reproductive-age women include ovulatory disorders and polycystic ovary syndrome (PCOS) (Goodman et al. 2001). Characterized by anovulation, menstrual irregularity and high androgen

\section{Key Words}

- $5 \alpha$-dihydrotestosterone

- hyperandrogenism/ hyperandrogenemia

- androgen receptor

- kisspeptin concentrations, PCOS is one of the most common hormonal disorders in women. It has been inferred that excess androgen observed in PCOS patients results from abnormalities in the hypothalamic-pituitary-gonadal (HPG) axis (Ehrmann 2005). Additionally, high levels of adrenal androgen are observed in $25 \%$ of PCOS patients 
(Moran et al. 2015). As women with hyperandrogenemia have varying degrees of ovulatory dysfunction (Steinberger et al. 1984, Goodman et al. 2001), it is possible that excessive androgens affect the HPG axis and cause ovarian dysfunction.

Encoded by the Kiss1 gene, kisspeptin and its receptor, G protein-coupled receptor 54 (GPR54), play a pivotal role in the regulation of ovulation and follicle development by stimulating release of gonadotrophin-releasing hormone (GnRH) and LH in mammals (Roa et al. 2011). Mutations in GPR54 cause hypogonadotropic hypogonadism in both humans and mice (de Roux et al. 2003, Funes et al. 2003, Seminara et al. 2003). In rodents, kisspeptin neurons are found primarily within the anteroventral periventricular nucleus (AVPV) and arcuate nucleus (ARC). AVPV kisspeptin neurons are considered to be a target of estrogen-positive feedback, responsible for the induction of preovulatory GnRH/LH surges. Conversely, ARC kisspeptin neurons mediate negative feedback actions of sex steroids upon GnRH/LH secretion. Moreover, in many mammals, ARC kisspeptin neurons also coexpress neurokinin B (NKB) and dynorphin (Dyn), designated as KNDy neurons, these cells are thought to be involved in the generation of pulsatile GnRH/LH secretions (Lehman et al. 2010a).

Manneras and coworkers reported that female rats continuously administered $5 \alpha$-dihydrotestosterone (DHT) from prepuberty to an adult age exhibited irregular estrus cycles (Manneras et al. 2007). In addition, hypothalamic kisspeptin immunoreactivity was reduced in female rats chronically exposed to DHT (Brown et al. 2012). To investigate whether chronic exposure to androgen in female rats affects kisspeptin expression in the AVPV and ARC or LH release, we utilized a chronic DHT exposure model in this study. Further, we performed the first investigation of androgen receptor (AR) expression within kisspeptin neurons in the AVPV and ARC of female rats. Previously, colocalization of AR in kisspeptin neurons have been revealed in the ARC of male mice and ewe (Lehman et al. 2010b, Smith et al. 2005) and in the AVPV of male mice (Clarkson et al. 2012).

\section{Materials and methods}

\section{Animals}

The present study was approved by Nippon Medical School's Committee on Animal Research. Female rats of Wistar-Imamichi strain (Institute for Animal Reproduction, Ibaraki, Japan) were housed in a controlled (14-h light/10-h dark, 06:00 lights on) environment with free access to food and water. For hyperandrogenic model animals, female rats (20-22 days of age) were implanted subcutaneously with 90-day continuousrelease pellets (Innovative Research of America, Sarasota, FL, USA) containing $7.5 \mathrm{mg}$ DHT (DHT rat) and weaned (Manneras et al. 2007). Other intact female animals were used for control groups (non-DHT). From 8 weeks of age, vaginal smears from all animals were checked daily until use in experiments. Studies were performed after 7-12 weeks of DHT implantation, when rats were 10-15 weeks of age. DHT pellets remained implanted until animals were killed. For double staining of Kiss1 and AR, female 7-week-old rats were utilized. Animals having shown at least 2 consecutive 4-day estrus cycles were used. All surgical procedures were performed under isoflurane anesthesia.

\section{Brain sectioning for AVPV or ARC}

For in situ hybridization studies and immunohistochemistry, every second section through the AVPV and periventricular hypothalamic nucleus (PeN) (from $0.48 \mathrm{~mm}$ anterior to $0.36 \mathrm{~mm}$ posterior to the bregma (Paxinos \& Watson 2007)) or every fourth section through ARC (from $1.72 \mathrm{~mm}$ to $4.36 \mathrm{~mm}$ posterior to the bregma) was used. Numbers of Kiss1-expressing or immunoreactive cells were manually counted under a light microscope (BX51 microscope, Olympus), and the sum of the cell number in brain sections was obtained. Details of GnRH immunohistochemistry are described below.

\section{In situ hybridization}

Kiss1 in situ hybridization was performed as previously described (Adachi et al. 2007). Briefly, animals were deeply anesthetized with sodium pentobarbital and saline was perfused through the heart, followed by $4 \%$ paraformaldehyde (PFA) in $0.05 \mathrm{M}$ phosphate buffer (PB) between 13:00 and 17:00. Intact brains were removed from skulls and stored in $4 \%$ PFA overnight at $4^{\circ} \mathrm{C}$. The following day, brains were immersed in $0.05 \mathrm{M}$ $\mathrm{PB}$ containing $30 \%$ sucrose at $4^{\circ} \mathrm{C}$ for 4 days to protect against cryodamage. Serial $50-\mu \mathrm{m}$ coronal sections containing AVPV or ARC were obtained. A Kiss1-specific digoxigenin (DIG)-labeled probe was used for free-floating in situ hybridization. A DIG-labeled antisense RNA probe was synthesized from full-length rat Kiss1 template cDNA 
A

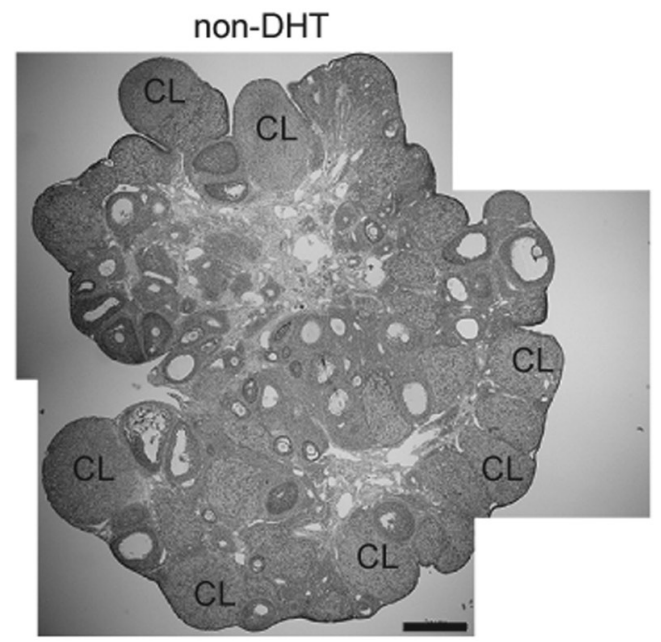

DHT

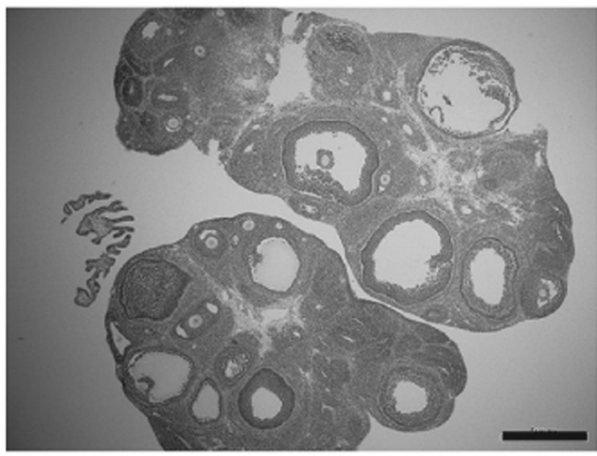

B
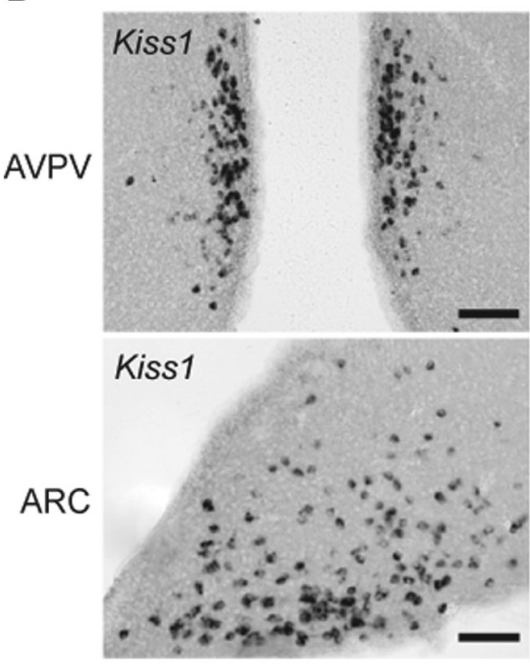

DHT

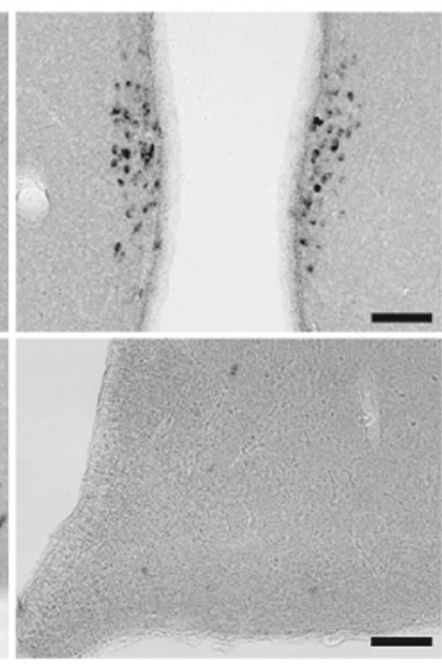

C
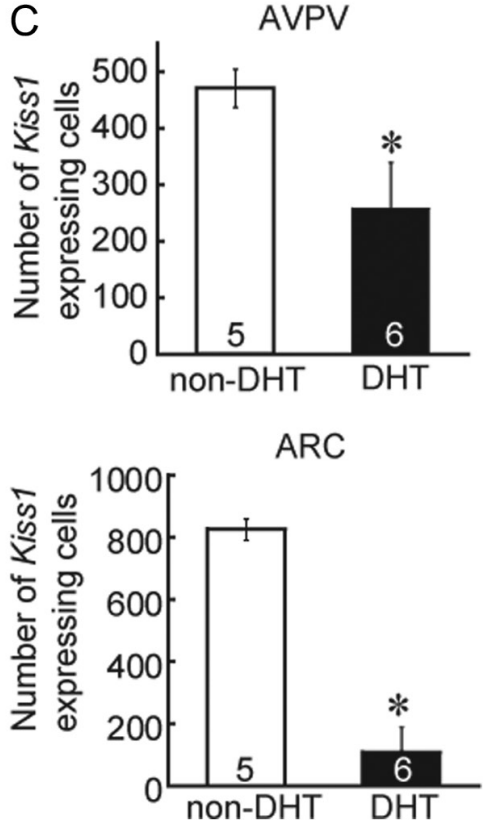

Figure 1

Morphology of ovaries and expression of Kiss1 mRNA in the anteroventral periventricular nucleus (AVPV) and arcuate nucleus (ARC) of ovary-intact rats. (A) Representative ovaries from non-DHT and DHT rats. Bars $=500 \mu \mathrm{m}$. CL, corpus luteum. (B) Kiss1 mRNA expression by in situ hybridization in the AVPV and ARC of non-DHT and DHT rats. Non-DHT, a normal control rat showing diestrus stage. DHT rats were ovary-intact animals. Bars $=100 \mu$ m.

(C) Histogram indicating number of cells expressing Kiss1 mRNA in the AVPV and ARC. Statistical differences were determined by unpaired Student's $t$-test. ${ }^{*} P<0.05$ vs non-DHT rats. Numbers in each column represent the number of animals examined. Values are expressed as mean \pm S.E.M.

(GeneBank accession \#AY196983) (Terao et al. 2004) using a DIG RNA labeling kit (Roche Diagnostics). Every second section through the AVPV and PeN, as well as every fourth section through the ARC, was hybridized with labeled probe $(1 \mu \mathrm{g} / \mathrm{mL}$ in hybridization buffer). To visualize DIG labeling, sections were incubated with an alkaline phosphatase (AP)-conjugated anti-DIG1 antibody (1:1000, Roche Diagnostics) for $2 \mathrm{~h}$ at $37^{\circ} \mathrm{C}$ and then placed in 4-nitroblue tetrazolium chloride/5-bromo-4chloro-3-indolyl phosphate solution (Roche Diagnostics).
Kiss1-expressing cells were manually counted under a light microscope.

\section{GnRH immunohistochemistry}

Serial 50- $\mu \mathrm{m}$ coronal sections containing the preoptic area (POA, from $0.12 \mathrm{~mm}$ to $0.72 \mathrm{~mm}$ anterior to the bregma) and median eminence (ME, from $2.64 \mathrm{~mm}$ to $3.12 \mathrm{~mm}$ posterior to the bregma) were obtained from rats as described in 'Experiment 2' section. Every second section 
A

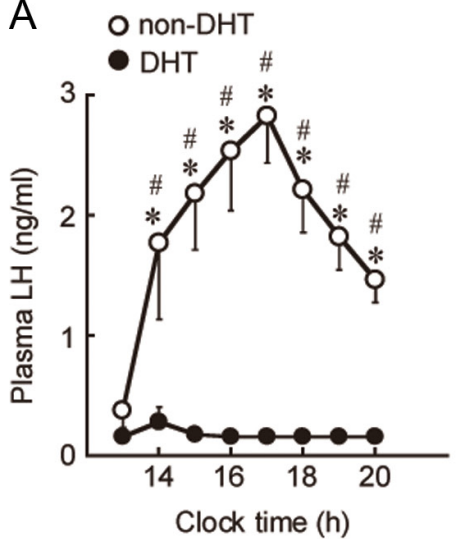

B

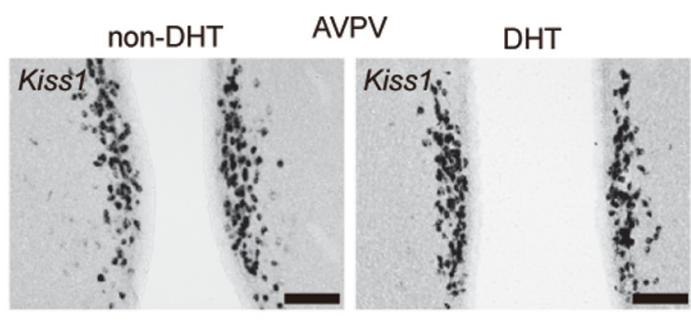

C

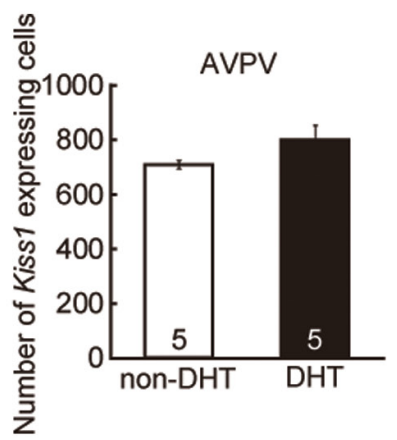

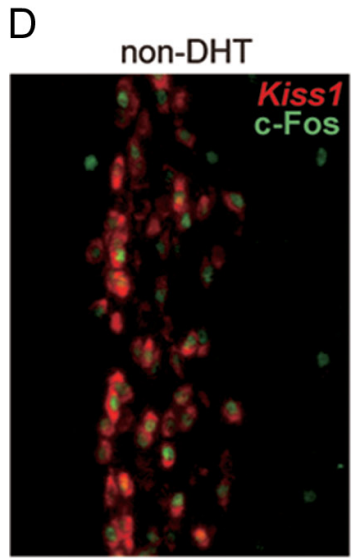

E

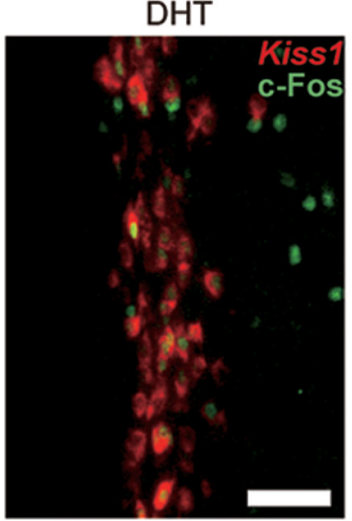

F
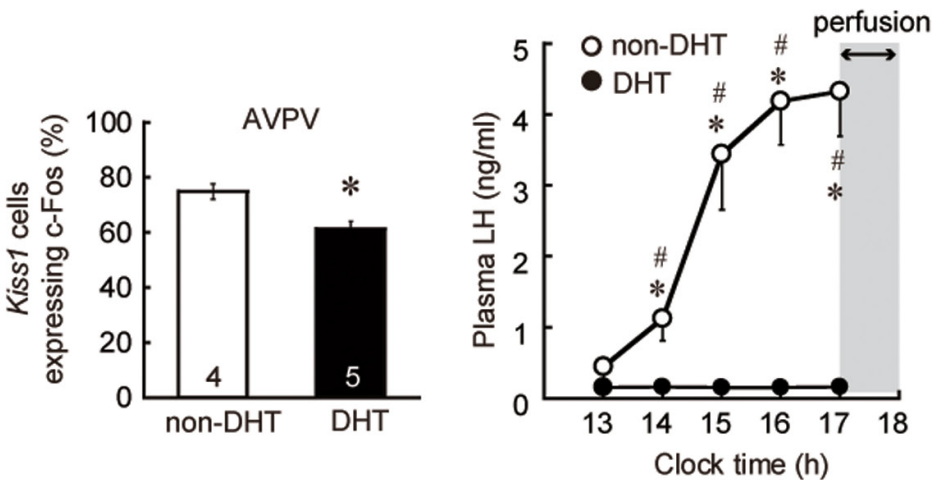

Figure 2

Estradiol-17 $\beta$ (E2)-induced luteinizing hormone (LH) surge and expression of Kiss1 mRNA in the AVPV of non-DHT and DHT rats. All animals were ovariectomized and implanted with tubes containing a high concentration of E2. (A) Changes in plasma LH levels were assessed in freely moving conscious rats from 13:00 to 20:00. Values are expressed mean \pm S.E.M. (each group, $n=9$ ). Statistical differences were determined by two-way repeatedmeasures ANOVA (clock time and group), followed by Bonferroni correction. ${ }^{\star} P<0.05$, vs $13: 00$. ${ }^{P}<0.05$, vs DHT rats. (B) Expression of Kiss1 mRNA by in situ hybridization in the AVPV of representative rats. Bars $=100 \mu \mathrm{m}$. (C) Number of Kiss1 mRNA-expressing cells in the AVPV. No significant difference was found between the two groups. Numbers in each column represent the number of animals examined. Values are expressed as mean \pm S.E.M. (D) Z-stack images of double staining for Kiss1 and c-Fos in the AVPV of representative rats. Kiss1 mRNA-expressing cells, red; c-Fos-ir cells, green. Bars $=50 \mu \mathrm{m}$. After blood sampling, animals were perfused from 17:00 to 18:00. (E) Percentage of c-Fos-ir cells to Kiss1 mRNA-expressing cells. Statistical differences were determined by unpaired Student's $t$-test. ${ }^{*} P<0.05$ vs non-DHT rats. Numbers in each column represent the number of animals examined. (F) Plasma LH levels of rats utilized for double staining of Kiss1 and c-Fos. Statistical analysis was performed as previously described for (A) (non-DHT, $n=4 ; \mathrm{DHT}, n=5$ ).

through the PoA and one section of median eminence were incubated with anti-GnRH antibody (1:1000, mouse monoclonal, provided by Dr Min Kyun Park, The University of Tokyo, Japan (Park \& Wakabayashi 1986)) for $24 \mathrm{~h}$ at $4^{\circ} \mathrm{C}$. Sections were washed and incubated with biotin-conjugated anti-mouse IgG (Histofine SAB-PO (M) Kit, Nichirei Biosciences, Tokyo, Japan) for $2 \mathrm{~h}$, followed by incubation in avidin-biotinylated horseradish peroxidase (HRP) complex (Histofine SAB-PO (M) kit) for $2 \mathrm{~h}$. GnRH immunoreactivity was visualized using 3'3-diaminobenzidine (DAB) mixed with $0.03 \%$ hydrogen peroxide. Photomicrographs were obtained using a BX51 microscope (Olympus) and images were exported in .tiff format. ImageJ software, version 1.46 (imajej.nih.gov), was used to measure the area of GnRH-ir fibers. GnRH-ir cells were manually counted under the light microscope.

\section{Neurokinin B (NKB) immunohistochemistry}

Serial 50- $\mu \mathrm{m}$ coronal sections containing ARC were obtained from animals as described in 'Experiment 2' section. Every fourth section through the ARC was incubated with anti-NKB antibody (1:2500, rabbit polyclonal, Novus Biologicals, Littleton, CO, USA) (Sawai et al. 2012) for $24 \mathrm{~h}$ at $4^{\circ} \mathrm{C}$. To visualize immunoreactive cells, a Histofine kit was used as previously described. 
A

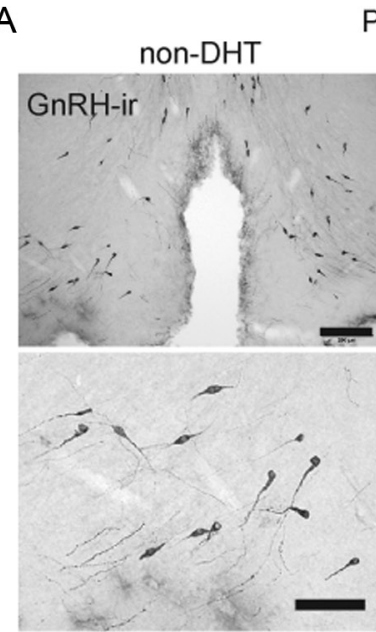

POA

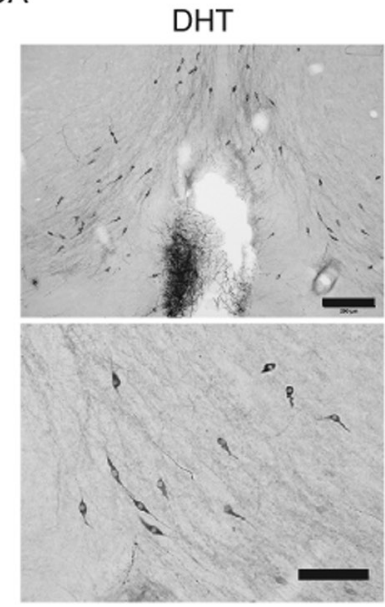

B

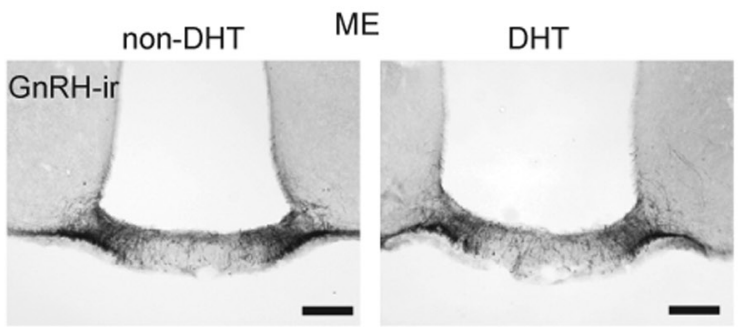

C

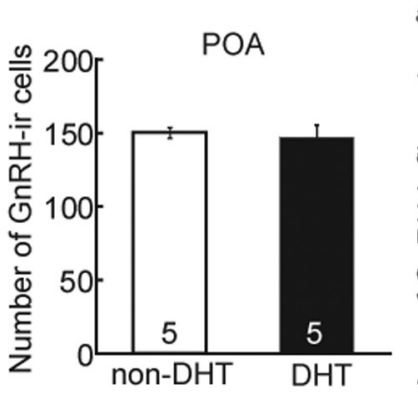

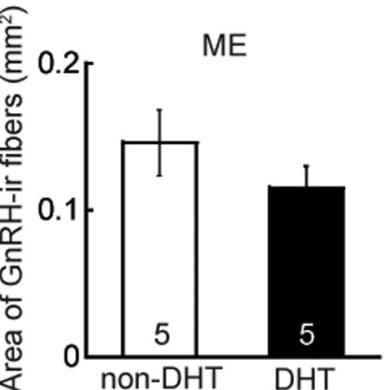

Figure 3

GnRH immunoreactivity in the preoptic area (POA) (A) and median eminence (ME) (B) of representative non-DHT and DHT rats. All animals were ovariectomized and implanted with a tube containing a high concentration of E2. Bars of upper panels $=200 \mu \mathrm{m}$. Lower panels are a higher magnification of upper panels. Bars $=100 \mu \mathrm{m}$ (A), $200 \mu \mathrm{m}$ (B). (C) Number of GnRH-immunoreactive (ir) cells in POA and area of GnRH-ir fibres in ME. No significant difference was found between the two groups. Numbers in each column represent the number of animals examined. Values are expressed as mean \pm S.E.M.

\section{Double-labeling fluorescence in situ hybridization (Kiss1) and immunohistochemistry (AR)}

After hybridization with a DIG-labeled antisense RNA probe for Kiss1 $(1 \mu \mathrm{g} / \mathrm{mL})$, sections were incubated with blocking buffer ( $1 \%$ bovine serum albumin (BSA) in $0.1 \mathrm{M}$ Tris-buffered saline (TBS)) for $1 \mathrm{~h}$ at $37^{\circ} \mathrm{C}$. Next, sections were washed with $0.1 \mathrm{M}$ phosphate-buffered saline (PBS), followed by incubation with rabbit anti-AR antibody (1:250, rabbit monoclonal, Epitomics, Burlingame, CA, USA) in $0.1 \mathrm{M}$ PBS overnight at $4^{\circ} \mathrm{C}$. The following day, sections were washed with $0.1 \mathrm{M}$ PBS and incubated with Alexa Fluor 488-conjugated donkey anti-rabbit IgG antibody (1:500, Thermo Fisher) and AP-conjugated antiDIG1 antibody (1:1000) in $0.1 \mathrm{M}$ PBS for $2 \mathrm{~h}$ at $37^{\circ} \mathrm{C}$. After a 5-min wash, DIG labeling was detected using a 2-hydroxy3-naphtholic acid-2'-phenylanilide phosphate (HNPP) fluorescent detection set (Roche Diagnostics). Fluorescence images were obtained using confocal laser microscopy (LSM710, Carl Zeiss). Immunoreactive cells were manually counted within single images displayed on a monitor. Cells were counted in every second section through the AVPV and every fourth section through the ARC.

\section{Double-labeling fluorescence in situ hybridization (Kiss1) and immunohistochemistry (c-Fos)}

The procedure is almost identical as performed for double staining of Kiss1 and AR. Briefly, after hybridization (probe concentration; $0.3 \mu \mathrm{g} / \mathrm{mL}$ ), sections were incubated with blocking buffer containing 5\% normal donkey serum for $1.5 \mathrm{~h}$ at $37^{\circ} \mathrm{C}$. After washing with $0.1 \mathrm{M}$ PBS, sections were incubated with mouse antic-Fos antibody (1:50, sc-166940, mouse monoclonal, Santa Cruz Biotechnology) in 0.1M PBS for 2 days at $4^{\circ} \mathrm{C}$. After washing, sections were incubated with Alexa Fluor 488-conjugated donkey anti-mouse IgG antibody (1:500, Thermo Fisher) and AP-conjugated anti-DIG1 antibody $(1: 2000)$ in $0.1 \mathrm{M}$ PBS for $2 \mathrm{~h}$ at $37^{\circ} \mathrm{C}$. DIG labeling was detected using a kit (Fast Red TR/Naphthol AS-MX Tablets, Sigma). Fluorescence images were obtained using confocal laser microscopy (LSM710). Z-stack images of each brain slice were acquired at $2.5-\mu \mathrm{m}$ intervals. Kiss1 cells with or without c-Fos immunoreactivity were manually counted on a monitor. Cells were counted in every second section through the AVPV ( $n=4-5$ per group).
๑ 2017 Society for Endocrinology Printed in Great Britain 
A

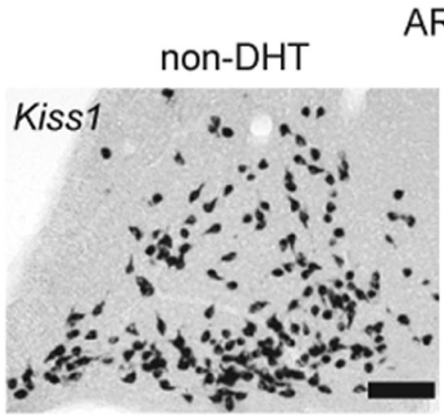

ARC

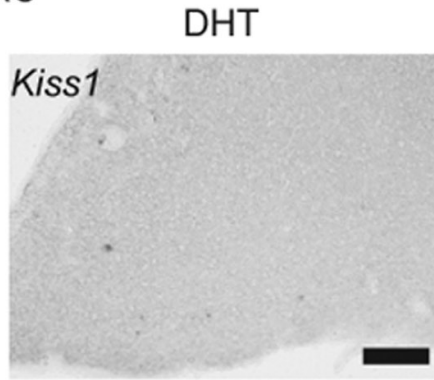

B ARC
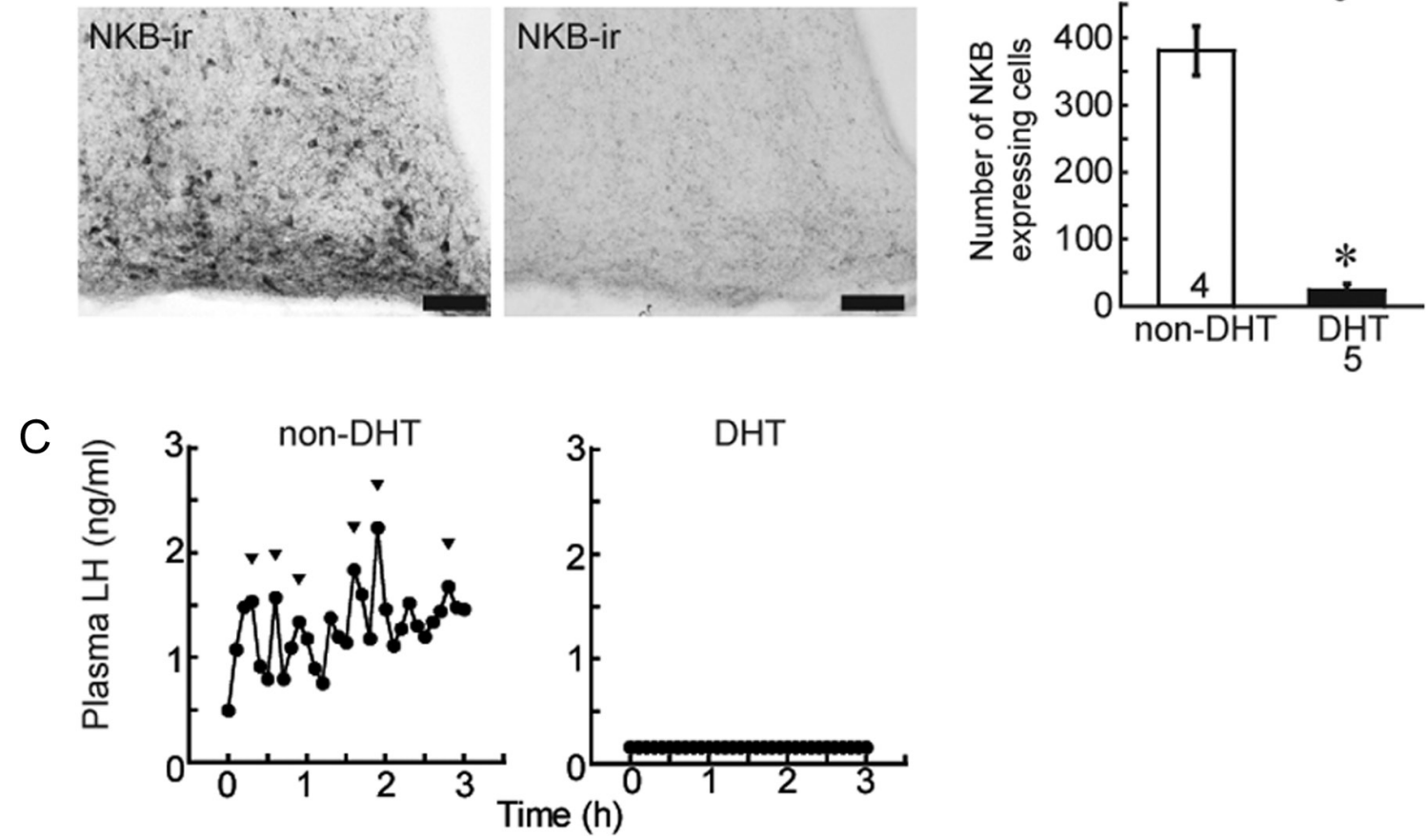

Figure 4

Expression of Kiss 1 mRNA and NKB-ir cells in the ARC and pulsatile LH secretion of non-DHT and DHT rats. All animals were ovariectomized. (A) Kiss1 mRNA-expressing cells (upper panels) and NKB-ir cells (lower panels) in the ARC. Bars $=100 \mu \mathrm{m}$. (B) Number of Kiss1 mRNA or NKB-ir cells in the ARC. Statistical differences were determined by unpaired Student's $t$-test. ${ }^{*} P<0.05$, vs non-DHT rats. Numbers in each column represent the number of animals examined. Values are expressed as mean \pm S.E.M. (C) Plasma LH profiles of representative non-DHT OVX and DHT OVX rats. Arrowheads indicate peaks of LH pulses identified by the PULSAR computer program.

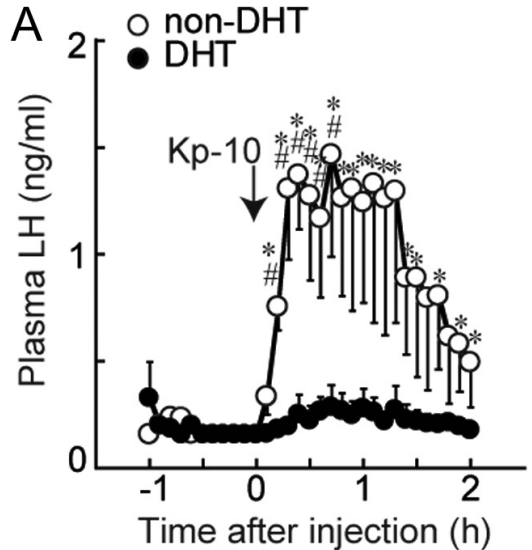

Figure 5

Effect of rat kisspeptin $10(\mathrm{kp}-10)$ and GnRH agonist on $\mathrm{LH}$ release in non-DHT and DHT rats. $\mathrm{Kp}-10$ was injected (arrow) into the third ventricle (3V) $1 \mathrm{~h}$ after commencing blood sampling. Buserelin, a GnRH agonist, was intravenously injected into rats $1 \mathrm{~h}$ after commencing blood sampling. Normal diestrus rats were used as a control group (non-DHT). DHT rats were ovary-intact animals. Statistical differences were determined by two-way repeated measures ANOVA (time and group), followed by Bonferroni correction. ${ }^{*} P<0.05$, vs blood sample just before $\mathrm{kp}-10$ or buserelin injection (time 0 ). ${ }^{\# P}<0.05$, vs DHT rats. Each group, $n=6$ (A). Non-DHT, $n=4$; DHT, $n=6$ (B). 



Figure 6

Expression of androgen receptor (AR) on kisspeptin neurons in the AVPV and ARC of female rats. Double staining for Kiss1 and AR in the AVPV (A) and ARC (B) of normal adult female rats. Lower panels show high magnification of each upper panel. Kiss1 mRNA-expressing cells, red; AR-ir cells, green. Arrowheads indicate coexpression of Kiss1 and AR. Bars $=50 \mu \mathrm{m}$.

\section{Ovarian histology}

Ovaries of all study animals were weighed, fixed in $4 \%$ PFA at $4^{\circ} \mathrm{C}$ and embedded in paraffin. Ovaries were serially sectioned at $5-\mu \mathrm{m}$ intervals. Every fifth section (DHT group) or every tenth section (non-DHT group) was mounted on a glass slide and stained with hematoxylin and eosin to confirm either the presence or absence of corpus luteum. Ovarian histology was verified under a light microscope.

\section{Brain surgery}

A guide cannula for third ventricle (3V) injection (23G; Plastic One, Roanoke, VA, USA) was stereotaxically implanted a week prior to experiments. Stereotaxic coordinates for the $3 \mathrm{~V}$ cannula, determined according to a rat brain atlas (Paxinos \& Watson 2007), were $0.8 \mathrm{~mm}$ posterior and $7.5 \mathrm{~mm}$ ventral to the bregma at midline. At the end of an experiment, an amount of $3 \%$ brilliant blue equal to that used during experiments was infused into 
the $3 \mathrm{~V}$ to verify cannula placement within each animal. Cannula location was also verified by visual inspection.

\section{LH assay}

Plasma LH concentrations were determined using a double-antibody radioimmunoassay (RIA) kit for rat $\mathrm{LH}$ provided by the National Hormone and Peptide Program (Baltimore, MD, USA). Values are expressed in terms of the National Institute of Diabetes and Digestive and Kidney Diseases rat LH-RP-3. Minimum detectable level for utilized sample size $(50 \mu \mathrm{L})$ was $0.156 \mathrm{ng} / \mathrm{mL}$, with intraassay and interassay coefficients of variation of $5.5 \%$ and $18.2 \%$, respectively, at $0.63 \mathrm{ng} / \mathrm{mL}$.

\section{Estradiol assay}

Plasma estradiol levels were measured using a commercial kit (Estradiol ELISA Kit, Cayman Chemical). Prior to perfusion, blood samples were collected from high E2-treated rats with a silicon cannula. Plasma $(100 \mu \mathrm{L})$ and standard samples for ELISA were extracted twice with diethyl ether and dissolved in ELISA buffer $(100 \mu \mathrm{L})$. Extracted samples were assayed in duplicate according to kit instructions. Minimum detectable level for the utilized sample size $(50 \mu \mathrm{L})$ was $6.6 \mathrm{pg} / \mathrm{mL}$. Intra-assay coefficients of variation were $8.7 \%$ and $10.3 \%$ at $550.0 \mathrm{pg} / \mathrm{mL}$ and $193.1 \mathrm{pg} / \mathrm{mL}$, respectively. All samples were assayed in a 96-well plate format.

\section{Experimental design}

Experiment 1 To determine the effect of chronic exposure to DHT on expression of Kiss1 mRNA within the AVPV and ARC of intact animals, DHT $(n=6)$ and nonDHT (diestrus, $n=5$ ) rats were perfused with $4 \%$ PFA under anesthesia for in situ hybridization.

Experiment 2 To determine whether high levels of estrogen are capable of inducing AVPV kisspeptin expression and LH surges in DHT rats, estrogen treatments and blood sampling were conducted as previously described (Homma et al. 2009). DHT $(n=9)$ and non-DHT $(n=9)$ rats were ovariectomized (OVX) and implanted with subcutaneous Silastic tubing (1.57$\mathrm{mm}$ inner diameter; 3.18-mm outer diameter; $25 \mathrm{~mm}$ in length; Dow Corning, Midland, MI, USA) filled with $\beta$-estradiol (Sigma Aldrich) dissolved in sesame oil (Sigma) at $20 \mu \mathrm{g} / \mathrm{mL}$ to produce negative feedback levels of plasma estradiol-17 $\beta$ (E2). After 4 days, tubing was replaced with Silastic tubing (1.02-mm inner diameter; 2.16-mm outer diameter; $20 \mathrm{~mm}$ in length; Dow Corning) containing crystalline E2 to produce positive feedback levels of plasma E2. Two days later, blood samples were collected through a silicon cannula $(0.5-\mathrm{mm}$ inner diameter; $1-\mathrm{mm}$ outer diameter; Shin-Etsu Polymer, Tokyo, Japan) inserted into the right atrium on the previous day. To detect $\mathrm{LH}$ surges, samples were collected every hour from 13:00 to 20:00 in unanesthetized and unrestrained conditions. Plasma was isolated by immediate centrifugation and stored at $-20^{\circ} \mathrm{C}$ until use in $\mathrm{LH}$ assays. The day after blood sampling, animals were perfused with 4\% PFA for subsequent use in Kiss1 in situ hybridization studies and GnRH immunohistochemistry ( $n=5$ per group). For double staining of Kiss 1 and c-Fos, plasma samples were collected every hour from 13:00 to $17: 00$ to detect $\mathrm{LH}$ surges. All animals were perfused from 17:00 to 18:00 (non-DHT, $n=4$; DHT, $n=5$ ).

Experiment 3 To determine the effect of chronic exposure to DHT on ARC kisspeptin expression and pulsatile LH secretion, blood samples $(100 \mu \mathrm{L})$ were collected through a silicon cannula 2 weeks after OVX (non-DHT, $n=4$; DHT, $n=5$ ) as previously described. Pulsatile LH secretions were detected by taking blood every $6 \mathrm{~min}$ for $3 \mathrm{~h}$, with samples being replaced by an equivalent volume of washed red blood cells (obtained from other rats) to maintain constant hematocrit levels. Plasma was immediately obtained by centrifugation and stored at $-20^{\circ} \mathrm{C}$ until assay for LH. The day after blood sampling, animals were perfused with 4\% PFA for Kiss1 in situ hybridization and immunohistochemistry analysis of NKB.

Experiment 4 To determine whether central injection of kisspeptin-10 (rat kp-10, Peptide Institute, Osaka, Japan) induces LH release in DHT rats, brain surgery was performed (non-DHT, $n=6$; ovary-intact DHT, $n=6$ ) as previously described; samples were obtained as described in 'Experiment 3' section. Kp-10 was injected into the $3 \mathrm{~V}$ of all animals $(1 \mathrm{nmol} / 2 \mu \mathrm{L}$ ultrapure water at a flow rate of $1 \mu \mathrm{L} / \mathrm{min}$ for $2 \mathrm{~min}$ ) using a microinfusion pump $1 \mathrm{~h}$ after commencing blood sampling. Samples were obtained every $6 \mathrm{~min}$ for $2 \mathrm{~h}$ after $\mathrm{kp}-10$ injection. Dosages of http://joe.endocrinology-journals.org DOI: 10.1530/JOE-16-0568
() 2017 Society for Endocrinology Printed in Great Britain
Published by Bioscientifica Ltd. 
kp-10 were based on a previous study (Pheng et al. 2009). Diestrus rats (non-DHT) served as controls.

Experiment 5 To determine the effect of a GnRH agonist on LH release in DHT rats, buserelin $(1 \mu \mathrm{g} / 0.1 \mathrm{~mL}$ in $0.05 \mathrm{M}$ PBS, Sigma) was administered intravenously to ovary-intact DHT $(n=6)$ or non-DHT (diestrus, $n=4)$ rats, $1 \mathrm{~h}$ after commencing blood sampling (Gajewska et al. 2002). Samples were obtained as described in 'Experiment 3' section and were collected for $2 \mathrm{~h}$ after buserelin administration.

Experiment 6 To examine AR expression in kisspeptin neurons in the AVPV and ARC of female rats, we performed double-labeling fluorescence in situ hybridization and immunohistochemistry analysis, as previously described. In detail, normal adult female rats (200-250g body weight (BW)) were perfused with 4\% PFA at the cycling stage of diestrus. Sections containing AVPV or ARC were hybridized with an antisense RNA probe for Kiss1 and stained with anti-AR antibody, as previously described.

\section{Statistical analysis}

All data are reported as mean \pm standard error of the mean (s.E.m.). Statistical differences in the number of Kiss1, GnRH-ir or NKB-ir cells (Figs 1C, 2C, 2E, 3C and 4B) between groups were determined using an unpaired Student's $t$-test. LH pulses were identified with PULSAR algorithms (Merriam \& Wachter 1982). Statistical differences in mean LH concentration, as well as frequency and amplitude of LH pulses, were determined by nonparametric Mann-Whitney $U$ test. LH surge (Fig. 2A and F), kp-10 injection (Fig. 5A) and buserelin administration (Fig. 5B) were evaluated with two-way repeated measures ANOVA (time and group (non-DHT or DHT)), followed by a Bonferroni correction.

\section{Results}

\section{Body weight, estrous cycles and ovaries}

At 10 weeks (55 days after DHT pellet implantation), DHT rats demonstrated a significant increase in BW compared with non-DHT rats $(239.1 \pm 3.4 \mathrm{~g}$ (non-DHT, $n=22)$ vs $303.7 \pm 5.7 \mathrm{~g}$ (DHT, $n=37) ; P<0.05$ ). Further, the majority of DHT rats exhibited persistent diestrus (81.0\%), whereas only $6.3 \%$ of DHT rats showed normal estrous cyclicity; estrous cycles recovered in some DHT rats showing persistent diestrus (12.7\%). For this study, DHT rats with persistent diestrus were utilized. Ovarian weight of DHT rats was significantly lower than that of non-DHT rats $(31.2 \pm 6.1 \mathrm{mg} / 100 \mathrm{gBW}$ (non-DHT, $n=23$ ) vs $6.6 \pm 0.7 \mathrm{mg} / 100 \mathrm{gBW}$ (DHT, $n=35$ ); $P<0.05$ ). Further, ovaries in DHT rats displayed no corpus luteum (Fig. 1A). Based on these results, and in agreement with a previous report (Manneras et al. 2007), DHT treatment induced an increase in BW, persistent diestrus and an absence of corpus luteum in ovaries.

\section{Distribution of Kiss1 mRNA in the AVPV and ARC of ovary-intact animals}

Although AVPV cells expressing Kiss1-mRNA were found in both groups (Fig. 1B), these cells were significantly suppressed in DHT rats compared with non-DHT rats (diestrus) (Fig. 1C). In the ARC, cells expressing Kiss1mRNA were also significantly suppressed in DHT rats compared with non-DHT rats (Fig. 1B and C).

\section{Expression of Kiss 1 mRNA in the AVPV and LH surge in response to high levels of estrogen}

To determine whether high concentrations of estrogen can induce an LH surge and expression of Kiss1 mRNA in the AVPV, animals were OVX and implanted with a tube containing E2. Figure $2 \mathrm{~A}$ demonstrates an $\mathrm{LH}$ surge induced by high E2 in non-DHT rats, whereas this surge was undetectable in DHT rats (two-way ANOVA interaction between group and clock time factors, $P<0.01$; main effect of clock time, $P<0.001$; main effect of group, $P<0.05)$. In non-DHT rats, plasma LH levels at 14:00 and thereafter were significantly higher than group levels at 13:00 $(P<0.05$, Bonferroni correction). In contrast, DHT rats showed very low plasma LH levels throughout the sampling period (not significant (NS), Bonferroni correction). The number of cells expressing Kiss1-mRNA in the AVPV did not vary significantly between the two groups (Fig. 2B and C). However, the percentage of Kiss1 cells expressing c-Fos was significantly lower in DHT rats compared with those in non-DHT rats (Fig. 2D and E). Change in plasma LH levels of rats utilized for double staining was identical to the result shown in Fig. 2A (Fig. 2F, two-way ANOVA interaction between group and clock time factors, $P<0.001$; main effect of clock time, $P<0.001$; main effect of group, $P<0.001)$. The number of counted Kiss1 cells did not differ significantly between groups (769.3 \pm 51.7 cells per animal (non-DHT) vs $618.2 \pm 88.1$

Published by Bioscientifica Ltd. 
cells per animal (DHT), unpaired Student's $t$-test). There were no statistically significant differences between groups with regard to number of GnRH-ir cells in the POA or calculated area of GnRH-ir fibers in the ME (Fig. 3). Plasma estradiol levels did not differ significantly between groups after high E2 treatment $(192.0 \pm 25.0 \mathrm{pg} / \mathrm{mL}$ (non-DHT, $n=9$ ) vs $210.4 \pm 21.8 \mathrm{pg} / \mathrm{mL}$ (DHT, $n=9$ ), unpaired Student's $t$-test).

\section{Expression of Kiss1 mRNA and NKB-ir cells in the ARC and pulsatile LH secretion}

To identify LH pulses and expression of Kiss1 mRNA in the ARC, non-DHT and DHT rats were ovariectomized and examined. Cells expressing Kiss1-mRNA or NKB were significantly decreased in the ARC of DHT rats compared with non-DHT rats (Fig. 4A and B). Further, pulsatile LH release was suppressed in DHT rats (Fig. 4C), resulting in a significant decrease in mean LH levels $(0.156 \pm 0.0002 \mathrm{ng} / \mathrm{mL}$, $n=4)$ compared with non-DHT rats $(1.265 \mathrm{ng} / \mathrm{mL}, n=4$, $P<0.05)$. Frequency of LH pulses was also significantly suppressed in DHT rats (0pulse $/ 3 \mathrm{~h}$ ) compared with non-DHT rats $(6.25 \pm 0.25$ pulses $/ 3 \mathrm{~h}, P<0.05)$, as was LH pulse amplitude $(0 \mathrm{ng} / \mathrm{mL}$ and $0.38 \pm 0.04 \mathrm{ng} / \mathrm{mL}$, respectively, $P<0.05$ ).

\section{Effect of kp-10 injection into $3 \mathrm{~V}$ on LH release in DHT rats}

To identify whether suppression of LH pulses was caused by decreased expression of Kiss1-mRNA in the ARC, kp-10 was injected into the $3 \mathrm{~V}$ of DHT rats. Kp-10 induced $\mathrm{LH}$ release in non-DHT rats (diestrus), while having no effect on LH release in DHT animals (Fig. 5A; main effect of time, $P<0.001$; main effect of group, $P<0.05$; interaction between group and time, $P<0.001)$. After kp-10 injection, plasma LH levels were higher than blood samples taken just before injection in non-DHT animals (post hoc Bonferroni correction, $P<0.05)$, whereas in DHT animals, LH levels remained unchanged after administration of kp-10.

\section{Effect of GnRH agonist (buserelin) on LH release in DHT rats}

As intracerebroventricular injection of $\mathrm{kp}-10 \mathrm{did}$ not affect LH release in DHT rats, buserelin (a GnRH agonist) was administered intravenously to DHT rats to identify the sensitivity to GnRH within the pituitary. Immediately after administration of buserelin, plasma LH levels were found to be elevated in diestrus non-DHT rats (Fig. 5B; main effect of time, $P<0.01$; main effect of group, $P<0.01$; interaction between group and time, $P<0.001)$. After buserelin injection, plasma LH levels were significantly higher than those before administration in non-DHT rats (post hoc Bonferroni correction, $P<0.05$ ), whereas plasma LH levels in DHT rats remained low and unvaried after buserelin injection.

\section{Coexpression of kisspeptin and AR in the AVPV and ARC}

We determined whether kisspeptin neurons express AR in the AVPV and ARC of normal adult female animals. Figure 6 shows double-labeling fluorescence in situ hybridization and immunohistochemistry analysis for Kiss1 and AR. Approximately $63.1 \pm 9.2 \%(n=4$, approximately $300-540$ cells per animal) of cells expressing Kiss1-mRNA in the ARC also expressed AR. In contrast, cells expressing Kiss 1-mRNA in the AVPV hardly expressed AR $(1.5 \pm 0.5 \%$, $n=6$, approximately $130-175$ cells per animal).

\section{Discussion}

We provide the first demonstration of Kiss1 neurons expressing ARs in the ARC of female rats. A previous study in male mice revealed a high percentage (64\%) of Kiss1-mRNA-expressing neurons also express AR mRNA; further, ARC Kiss1-mRNA expression was reduced by DHT treatment in castrated mice (Smith et al. 2005). In the present study, both Kiss1 and NKB expression in the ARC of rats was reduced by DHT. Moreover, LH pulses were suppressed and estrous cycles manifested as persistent diestrus in these animals. As kisspeptin and $\mathrm{NKB}$ neurons in the ARC are believed to be involved in LH pulse generation, our results suggest androgen inhibits kisspeptin and NKB expression through ARs in the ARC, leading to suppression of pulsatile LH secretion.

In contrast to the ARC, few kisspeptin neurons expressed ARs in the AVPV of female rats. Thus, AVPV kisspeptin neurons were detected in the context of high E2 treatment, even in female rats exhibiting hyperandrogenemia. In ovary-intact DHT rats, a decrease in the number of Kiss1-expressing cells in the AVPV appears to be associated with a decrease in endogenous estrogen. Although no difference in expression of AVPV kisspeptin neurons was observed, the percentage of kisspeptin neurons expressing c-Fos was significantly lower in DHT rats. Thus, androgen may indirectly affect

Published by Bioscientifica Ltd. 
AVPV kisspeptin neurons. However, approximately $60 \%$ of kisspeptin neurons in DHT rats expressed c-Fos, whereas an LH surge was undetected. Additionally, in one out of five DHT rats, approximately 71\% of kisspeptin neurons expressed c-Fos, whereas an LH surge was undetectable similar to other DHT rats. Thus, suppression of LH surges elicited by androgen may primarily be the result of pathways other than inhibition of AVPV kisspeptin neurons. Indeed, AVPV kisspeptin neurons seem to be indirectly affected by androgen because of an absence of AR. However, we did not investigate whether AVPV kisspeptin neurons express membrane androgen receptors, and thus, it remains possible that androgen directly affects AVPV kisspeptin neurons.

Although AVPV kisspeptin neurons are a target of estrogen-positive feedback to induce GnRH/LH surges (Homma et al. 2009), no LH surge was detected after high E2 treatment in DHT rats. As our results demonstrate, GnRH agonist-induced LH release is suppressed in DHT rats, chronic exposure to androgen may impair pituitary responses to GnRH. In primary pituitary cultures from monkeys and rats, ARs are expressed in gonadotrophs (Okada et al. 2003); thus, it is possible that androgen directly inhibits gonadotropin release in the pituitary of female animals. Further, as female patients exhibiting hypogonadotropic hypogonadism due to an inactivating mutation in KISS1 have blunted LH and follicle-stimulating hormone (FSH) responses to GnRH (Topaloglu et al. 2012), reduced responses to $\mathrm{GnRH}$ may be associated with a reduction in the expression of kisspeptin in ARC neurons. Hence, chronic suppression of pulsatile LH secretion may reduce pituitary responsiveness to GnRH. Although present studies indicate single-shot injections of GnRH agonist or kp-10 do not induce LH release in DHT rats, it appears that LH levels were slightly increased by $\mathrm{GnRH}$ agonist. At least, DHT rats in this study showed disruption at both the hypothalamic and pituitary level, which may be associated with the suppression of LH surges induced by high E2. However, we cannot deny the possibility that GnRH and/or kisspeptin priming may evoke high E2-induced LH surges in DHT rats.

Our results indicate chronic exposure to DHT suppresses pulsatile LH secretion in female rats, whereas women with PCOS appear to have high LH secretion in relation to FSH (Abbott et al. 2009). Results of the present study did not fit into characteristics of PCOS patients. Testosterone has been shown to suppress LH and FSH secretion independent of peripheral aromatization in both men (Santen 1975, Marynick et al. 1979) and women (Serafini et al. 1986, Spinder et al. 1989). In one report, a woman with undiagnosed virilizing lipoid-cell ovarian tumor exhibited low basal gonadotropin levels with no discernible pulsatility or response to GnRH (Barkan et al. 1984). Thus, androgen seems to suppress pituitary gonadotropin secretion in both sexes.

AVPV kisspeptin neurons barely expressed ARs in female rats, whereas ARs are expressed in the majority of kisspeptin neurons in the rostral periventricular area of $3 \mathrm{~V}$, a target of estradiol-positive feedback mechanism, in male mice (Clarkson et al. 2012). There may be a difference between mice and rats. Further studies are needed to confirm sex or species differences on AR expression in kisspeptin neurons.

In conclusion, our study proved excessive androgen levels suppress kisspeptin expression in the ARC, resulting in subsequent suppression of LH pulses. In contrast, kisspeptin neurons in the AVPV appear to be directly unaffected by androgen. The mechanism underlying suppression of high E2-induced LH surges in DHT rats may involve disruption at both the hypothalamic and pituitary level. Hence, hyperandrogenemia may be associated with anovulation and menstrual irregularities by adversely affecting ARC kisspeptin neurons and, conceivably, pituitary function.

Declaration of interest

The authors declare that there is no conflict of interest that could be perceived as prejudicing the impartiality of the research reported.

\section{Funding}

This work was supported by Grants-in-Aid from JSPS (24790240, 15K18979 to Iwata K, 22590230, 26460323 to Ozawa H) and the MEXT-supported Program for Strategic Research Foundation at Private Universities.

\section{Acknowledgements}

The authors are grateful to Dr Kei-ichiro Maeda (The University of Tokyo), Dr Hiroko Tsukamura (Nagoya University) and Dr Yoshihisa Uenoyama (Nagoya University) for providing RI-labeled LH for RIA and to Takeda Pharmaceutical Company Ltd. for kindly providing rat Kiss1 cDNA.

\section{References}

Abbott DH, Tarantal AF \& Dumesic DA 2009 Fetal, infant, adolescent and adult phenotypes of polycystic ovary syndrome in prenatally androgenized female rhesus monkeys. American Journal of Primatology 71 776-784. (doi:10.1002/ajp.20679)

Adachi S, Yamada S, Takatsu Y, Matsui H, Kinoshita M, Takase K, Sugiura H, Ohtaki T, Matsumoto H, Uenoyama Y, et al. 2007 Involvement of anteroventral periventricular metastin/kisspeptin neurons in estrogen positive feedback action on luteinizing hormone release 
in female rats. Journal of Reproduction and Development 53 367-378. (doi:10.1262/jrd.18146)

Barkan AL, Cassorla F, Loriaux DL, Kelch RP \& Marshall JC 1984 Steroid and gonadotropin secretion in a patient with a 30-year history of virilization due to lipoid-cell ovarian tumor. Obstetrics and Gynecology 64 287-295.

Brown RE, Wilkinson DA, Imran SA, Caraty A \& Wilkinson M 2012 Hypothalamic kiss1 mRNA and kisspeptin immunoreactivity are reduced in a rat model of polycystic ovary syndrome (PCOS). Brain Research 1467 1-9. (doi:10.1016/j.brainres.2012.05.049)

Clarkson J, Shamas S, Mallinson S \& Herbison AE 2012 Gonadal steroid induction of kisspeptin peptide expression in the rostral periventricular area of the third ventricle during postnatal development in the male mouse. Journal of Neuroendocrinology $\mathbf{2 4}$ 907-915. (doi:10.1111/j.1365-2826.2012.02294.x)

de Roux N, Genin E, Carel JC, Matsuda F, Chaussain JL \& Milgrom E 2003 Hypogonadotropic hypogonadism due to loss of function of the KiSS1-derived peptide receptor GPR54. PNAS 100 10972-10976. (doi:10.1073/pnas.1834399100)

Ehrmann DA 2005 Polycystic ovary syndrome. New England Journal of Medicine 352 1223-1236. (doi:10.1056/NEJMra041536)

Funes S, Hedrick JA, Vassileva G, Markowitz L, Abbondanzo S, Golovko A, Yang S, Monsma FJ \& Gustafson EL 2003 The KiSS-1 receptor GPR54 is essential for the development of the murine reproductive system. Biochemical and Biophysical Research Communications 312 1357-1363. (doi:10.1016/j.bbrc.2003.11.066)

Gajewska A, Siawrys G, Bogacka I, Przala J, Lerrant Y, Counis R \& Kochman K 2002 In vivo modulation of follicle-stimulating hormone release and beta subunit gene expression by activin A and the GnRH agonist buserelin in female rats. Brain Research Bulletin 58 475-480. (doi:10.1016/S0361-9230(02)00821-3)

Goodman NF, Bledsoe MB, Cobin RH, Futterweit W, Goldzieher JW, Petak SM, Smith KD, Steinberger E \& American Association of Clinical Endocrinologists Hyperandrogenic Disorders Task F 2001 American Association of Clinical Endocrinologists medical guidelines for the clinical practice for the diagnosis and treatment of hyperandrogenic disorders. Endocrine Practice 7 120-134. (doi:10.4158/EP.7.2.120)

Homma T, Sakakibara M, Yamada S, Kinoshita M, Iwata K, Tomikawa J, Kanazawa T, Matsui H, Takatsu Y, Ohtaki T, et al. 2009 Significance of neonatal testicular sex steroids to defeminize anteroventral periventricular kisspeptin neurons and the GnRH/LH surge system in male rats. Biology of Reproduction 81 1216-1225. (doi:10.1095/ biolreprod.109.078311)

Lehman MN, Coolen LM \& Goodman RL 2010a Minireview: kisspeptin/ neurokinin B/dynorphin (KNDy) cells of the arcuate nucleus: a central node in the control of gonadotropin-releasing hormone secretion. Endocrinology 151 3479-3489. (doi:10.1210/en.2010-0022)

Lehman MN, Merkley CM, Coolen LM \& Goodman RL 2010 $b$ Anatomy of the kisspeptin neural network in mammals. Brain Research 1364 90-102. (doi:10.1016/j.brainres.2010.09.020)

Manneras L, Cajander S, Holmang A, Seleskovic Z, Lystig T, Lonn M \& Stener-Victorin E 2007 A new rat model exhibiting both ovarian and metabolic characteristics of polycystic ovary syndrome. Endocrinology 148 3781-3791. (doi:10.1210/en.2007-0168)

Marynick SP, Loriaux DL, Sherins RJ, Pita JC Jr \& Lipsett MB 1979 Evidence that testosterone can suppress pituitary gonadotropin secretion independently of peripheral aromatization. Journal of Clinical Endocrinology and Metabolism 49 396-398. (doi:10.1210/jcem-49-3-396)

Merriam GR \& Wachter KW 1982 Algorithms for the study of episodic hormone secretion. American Journal of Physiology 243 E310-E318.
Moran C, Arriaga M, Arechavaleta-Velasco F \& Moran S 2015 Adrenal androgen excess and body mass index in polycystic ovary syndrome. Journal of Clinical Endocrinology and Metabolism 100 942-950. (doi:10.1210/jc.2014-2569)

Okada Y, Fujii Y, Moore JP Jr \& Winters SJ 2003 Androgen receptors in gonadotrophs in pituitary cultures from adult male monkeys and rats. Endocrinology 144 267-273. (doi:10.1210/en.2002-220770)

Park MK \& Wakabayashi K 1986 Preparation of a monoclonal antibody to common amino acid sequence of LHRH and its application. Endocrinologia Japonica 33 257-272. (doi:10.1507/endocrj1954.33.257)

Paxinos G \& Watson C 2007 The Rat Brain in Stereotaxic Coordinates, edn 6. San Diego, CA, USA: Academic Press.

Pheng V, Uenoyama Y, Homma T, Inamoto Y, Takase K, YoshizawaKumagaye K, Isaka S, Watanabe TX, Ohkura S, Tomikawa J, et al. 2009 Potencies of centrally- or peripherally-injected full-length kisspeptin or its C-terminal decapeptide on LH release in intact male rats. Journal of Reproduction and Development 55 378-382. (doi:10.1262/jrd.20240)

Roa J, Navarro VM \& Tena-Sempere M 2011 Kisspeptins in reproductive biology: consensus knowledge and recent developments. Biology of Reproduction 85 650-660. (doi:10.1095/biolreprod.111.091538)

Santen RJ 1975 Is aromatization of testosterone to estradiol required for inhibition of luteinizing hormone secretion in men? Journal of Clinical Investigation 56 1555-1563. (doi:10.1172/JCI108237)

Sawai N, Iijima N, Takumi K, Matsumoto K \& Ozawa H 2012 Immunofluorescent histochemical and ultrastructural studies on the innervation of kisspeptin/neurokinin B neurons to tuberoinfundibular dopaminergic neurons in the arcuate nucleus of rats. Neuroscience Research 74 10-16. (doi:10.1016/j. neures.2012.05.011)

Seminara SB, Messager S, Chatzidaki EE, Thresher RR, Acierno JS Jr , Shagoury JK, Bo-Abbas Y, Kuohung W, Schwinof KM, Hendrick AG, et al. 2003 The GPR54 gene as a regulator of puberty. New England Journal of Medicine 349 1614-1627. (doi:10.1056/NEJMoa035322)

Serafini P, Silva PD, Paulson RJ, Elkind-Hirsch K, Hernandez M \& Lobo RA 1986 Acute modulation of the hypothalamic-pituitary axis by intravenous testosterone in normal women. American Journal of Obstetrics and Gynecology 155 1288-1292. (doi:10.1016/00029378(86)90161-4)

Smith JT, Dungan HM, Stoll EA, Gottsch ML, Braun RE, Eacker SM, Clifton DK \& Steiner RA 2005 Differential regulation of KiSS-1 mRNA expression by sex steroids in the brain of the male mouse. Endocrinology 146 2976-2984. (doi:10.1210/en.2005-0323)

Spinder T, Spijkstra JJ, van den Tweel JG, Burger CW, van Kessel H, Hompes PG \& Gooren LJ 1989 The effects of long term testosterone administration on pulsatile luteinizing hormone secretion and on ovarian histology in eugonadal female to male transsexual subjects. Journal of Clinical Endocrinology and Metabolism 69 151-157. (doi:10.1210/jcem-69-1-151)

Steinberger E, Smith KD \& Rodriguez-Rigau LJ 1984 Testosterone, dehydroepiandrosterone, and dehydroepiandrosterone sulfate in hyperandrogenic women. Journal of Clinical Endocrinology and Metabolism 59 471-477. (doi:10.1210/jcem-59-3-471)

Terao Y, Kumano S, Takatsu Y, Hattori M, Nishimura A, Ohtaki T \& Shintani Y 2004 Expression of KiSS-1, a metastasis suppressor gene, in trophoblast giant cells of the rat placenta. Biochimica et Biophysica Acta 1678 102-110. (doi:10.1016/j.bbaexp.2004.02.005)

Topaloglu AK, Tello JA, Kotan LD, Ozbek MN, Yilmaz MB, Erdogan S, Gurbuz F, Temiz F, Millar RP \& Yuksel B 2012 Inactivating KISS1 mutation and hypogonadotropic hypogonadism. New England Journal of Medicine 366 629-635. (doi:10.1056/NEJMoa1111184)

Received in final form 25 March 2017

Accepted 4 April 2017

Accepted Preprint published online 4 April 2017 http://joe.endocrinology-journals.org

DOI: 10.1530/JOE-16-0568
๑ 2017 Society for Endocrinology Printed in Great Britain 